\title{
Renewable Biodiesel Production from Oleaginous Yeast Biomass Using Industrial Wastes
}

\author{
Sasithorn Kongruang ${ }^{1, *}$, Sittiruk Roytrakul ${ }^{2}$, and Malinee Sriariyanun ${ }^{3}$ \\ ${ }^{1}$ Bioprocess Engineering and Biotechnology Center, Department of Biotechnology, Faculty of Applied Science, King Mongkut's \\ University of Technology North Bangkok, Bangkok, Thailand \\ ${ }^{2}$ Department of Electrical and Computer Engineering, Faculty of Engineering, King Mongkut's University of Technology North \\ Bangkok, Bangkok, Thailand \\ ${ }^{3}$ Chemical and Process Engineering Program, The Sirindhorn International Thai-German Graduate School of Engineering, King \\ Mongkut's University of Technology North Bangkok, Bangkok, Thailand
}

\begin{abstract}
The accumulation lipid from oleaginous microorganisms is recognized as a second generation fuel. Biooil is known to as intracellular product of oily yeast utilizing various carbon substrates and converting different quantities of lipids in the form of triacylglycerols. This second generation fuel can be used to make biodiesel via a transesterification process. This study investigated the morphological characteristics of eight strains of Thai oleaginous yeasts via microscopy and analyzed the fatty acid profiling of yeasts cultured in three carbon sources: glucose, sugar cane molasses and crude glycerol in order to estimate biodiesel properties. To approach this goal, batch fermentations were used to culture eight yeast strains, Rhodosporidium toruloides TISTR 5123, TISTR 5154, TISTR 5149, Yarrowia lipolytica TISTR 5054, TISTR 5151, TISTR 5621, Rhodotorula glutinis TISTR 5159 and Rhodotorula graminis TISTR 5124 for $96 \mathrm{~h}$ under $30^{\circ} \mathrm{C}$ at $250 \mathrm{rpm}$. Result revealed that eight yeast strains contained significant amounts of fatty acids and lipids and accumulated mainly palmitic acid (C16:0), stearic acid (C18:0), oleic acid (C 18:1) and linoleic acid (C18:2), and they are suitable for the production of biodiesel. Fatty acid productions and profiles indicated that these yeast strains can be potentially used as the triacylglycerols producers for biodiesel production.
\end{abstract}

\section{Introduction}

Currently, soybean, rapeseed and palm oil are the main feedstock for biodiesel production in America, Europe and Asia [1]. These feedstocks are commonly applied to biodiesel fuel production via transesterification. Alternatively, oleaginous microorganisms are including bacteria, yeast, fungi and algae. Microorganisms are commercially used as interesting sources for biooil production [2]. Especially for oleaginous yeast which is the well-known microbial oil organism because they produced more than $20 \%$ of their biomass into intracellular lipid.

These microorganisms produce triacylglycerol and many type of fatty acids depending on cultivation media and stress under the growth. The similarity of triacylglycerols (TAGs) of the biooil from vegetable oils have increasing the interest to use these fatty acid compositions to further synthesis a mixture of fatty acid methyl esters (FAMEs) in to biodiesel [3]. Soccool et al., 2017 [4] reported that approximately a hundred microorganisms have already been recognized as producers. Some examples include Rhodotorula gracilis, Crytococcus curvatus, Yarrowia lipolytica, Rhodosporidium toruloides, Trichosporon capitatum, Cunninghamella echinulate, Candida curvata and Mucor sp. [4-6]. Among these strains, Rhodosporidium toruloides produced lipids at 55-68\% [7, 8]. For Yarrowia lipolytica strains, their intracellular lipids are approximately $30-43 \%[9,10]$. Moreover, Meng, 2009 reported that Rhodotorula gracilis contained $72 \%$ of lipid in their biomass. Most of these microorganisms produced biolipids more than $30 \%$ that have been using many sugars as raw materials for biodiesel production [3, 11, 12]. To increase the feasibility to produce biooil, finding other glucose sources for cultivation from industrial wastes, such as molasses and crude glycerol should be explored.

Several investigations have been explored opportunity to use molasses and crude glycerols as the main substrates for production $[13,14]$. The important parameters of feedstock to produce biodiesel is not only the total quality of fatty acid accumulation during the cultivation, but also the quantity of the fatty acid. In terms of yeast species, nutritional compositions (as carbon/nitrogen), cultivation time and temperature play a pivotal role in lipid content and each type of fatty acid composition to the biodiesel quality $[1,15,16]$. Type of microorganism, substrate and culture condition significantly affect composition of fatty acid, a basic factor that influence biodiesel properties [17].

To maintain quality of biodiesel, several properties must be evaluated and compared with the international

"Corresponding author: sasithorn.k@sci.kmutnb.ac.th 
biodiesel standard specification. Some of these properties include viscosity, specific gravity, cloud point, cetane number, iodine number and higher heating value (HHV). Quality standard of biodiesel have been defined by several countries such as American Standards for Testing Materials (ASTM 6751-3), European Union (EN 14214) and Germany (DIN 51606).

Depending upon the global standard of biodiesel quality, chain length, degree of unsaturation and branching are the key characteristics. They contribute to determine the quality of biodiesel. The comparison of biodiesel of our study yeast strains under two different types of industrial wastes have to be evaluated to compare with European (MS14214) and American standards (ASTM D6751). In this study, eight Thai screening oleaginous yeasts were studied for the ability to grow and produce intracellular lipids using industrial wastes (molasses and crude glycerol) as a renewable energy, in order to develop a microbial process for TAGs production. Fatty acid profiling from the utilization of various yeast strains using molasses, crude glycerol and glucose were reported.

\section{Materials and methods}

\subsection{Industrial waste materials}

Molasses was obtained from Singburi Sugar Co., Ltd. (Singburi, Thailand). Preliminary analysis of composition composed of $32 \%$ sucrose, $14 \%$ glucose $16 \%$ fructose, $10 \%$ total nitrogen, $10 \%$ of trace minerals as $0.5 \% \mathrm{SiO}_{2}, 3.5 \% \mathrm{~K}_{2} \mathrm{O}, 1.5 \% \mathrm{CaO}, 0.1 \% \mathrm{MgO}, 0.2 \%$ $\mathrm{P}_{2} \mathrm{O}_{5}, 0.2 \% \mathrm{Fe}_{2} \mathrm{O}_{3}, 1.6 \% \mathrm{SO}_{3} 0.4 \%$ Chlorides with $20 \%$ water. Total soluble solid contained $88{ }^{0} \mathrm{Brix}$, pH 5.4. Crude glycerol was received from Pathum Vegetable Oil Co., Ltd, Thailand. Composition composed of $85.90 \%$ glycerol, $4.8 \% \mathrm{NaCl}, 9.9 \%$ moisture content, $0.04 \%$ fatty acid and ester, $\mathrm{pH} 6.4$ with specific gravity of 1.2564 g.cm ${ }^{-3}$.

\subsection{Microorganism}

Rhodosporidium toruloides TISTR 5123, 5154 and 5149 Yarrowia lipolytica TISTR 5054, 5151, 5621, Rhodoturola glutinis TISTR 5159 and Rhodoturola graminis TISTR 5124 were purchased from Thailand Institute of Scientific and Technological Research. Yeast culture incubated in yeast malt agar at $30^{\circ} \mathrm{C}$ for $48 \mathrm{~h}$ was observed and photographed by using the light microscopy with amplification at $1000 x$.

\subsection{Inoculum preparation}

Yeast strains were revived from lyophilized vials and grown on yeast malt agar (YMA) plates. Seed preparation was transferred from the stock solution to YMA slants and incubated for 2 days at $30^{\circ} \mathrm{C}$. Following this period, colonies were transferred into the yeast malt broth and incubated for $48 \mathrm{~h}$ before transferring the $10 \%$ of inoculums in $100 \mathrm{~mL}$ of media: $10 \mathrm{~g} / \mathrm{L}$ glucose, $3 \mathrm{~g} / \mathrm{L}$ yeast extract, $3 \mathrm{~g} / \mathrm{L}$ malt extract and $5 \mathrm{~g} / \mathrm{L}$ peptone. Cultures were then incubated at $30^{\circ} \mathrm{C}$ in a shaking incubator with the shaking speed of $200 \mathrm{rpm}$ for $48 \mathrm{~h}$. For carbon source comparison, glucose, molasses and crude glycerol, the compositional of modified media were prepared as $20 \mathrm{~g} / \mathrm{L}$ carbon source, $1 \mathrm{~g} / \mathrm{L}$ yeast extract, $1 \mathrm{~g} / \mathrm{L}\left(\mathrm{NH}_{4}\right)_{2} \mathrm{SO}_{4}, 0.5 \mathrm{~g} / \mathrm{L} \mathrm{KH}_{2} \mathrm{PO}_{4}$. A series of $100 \mathrm{~mL}$ modified media experiments were inoculated with $1 \% \mathrm{v} / \mathrm{v}$ inoculum then incubated in shaking incubator at $200 \mathrm{rpm}$ at $30^{\circ} \mathrm{C}$ for $48 \mathrm{~h}$. Each sample was collected after centrifugation at $6,000 \mathrm{rpm}$ for $15 \mathrm{~min}$ and analyzed in triplicate. Biomass was determined by measuring the dry weight.

\subsection{Analytical methodology}

\subsubsection{Cell growth}

$5 \mathrm{~mL}$ cultures were harvested from each media by centrifugation at $6,000 \mathrm{rpm}$ for 15 minutes then discarded the supernatant. All precipitate was kept and wash with $0.85 \%$ saline water subsequently with the same volume of water. All samples were dried at $80^{\circ} \mathrm{C}$. The biomass was determined gravimetrically.

\subsubsection{Determination of lipids and the fatty acid profile (FAME)}

Lipid from dry cell weight biomass were extracted according to the method of Bligh and Dyer (1959) [18]. The extracted lipid fraction was esterified to obtain the fatty acid methyl esters. Analyses were performed in triplicate. FAME were analyzed in a gas chromatography equipped with FID (flame ionization detection) and the capillary column DB-Wax $(30 \mathrm{~m}$ length $\times 0.25 \mathrm{~mm}$ internal diameter $\mathrm{x} 0.2 \mu \mathrm{m}$ film thickness). Temperatures of the detector and injector were $230^{\circ} \mathrm{C}$ at $3{ }^{\circ} \mathrm{C} / \mathrm{min}$. The following temperature program was used for the separation of FAME: $100^{\circ} \mathrm{C}$ for 1 minute, with a gradual increase of $2^{\circ} \mathrm{C}$ per minute until the final temperature of $230^{\circ} \mathrm{C}$, where it was held for 18 minutes. The carrier gas was helium with constant flow. Volume of injection was 1 microliter with split rate of $1: 100$. The identification of FAME was evaluated using Supelco 37 Component Fame Mix, C4-C24 alkane as standard.

\subsection{Biodiesel criteria}

The biodiesel properties based on the quality and the percent composition of FAME from extracted lipid material from intracellular oleaginous yeast in different culture condition. The evaluation was performed on the calculation of individual characteristic properties of biodiesel [1].

The quality factors evaluated were viscosity, specific gravity, cloud point, cetane number, iodine number and higher heating value. The parameters were compared with the limit values stipulated according to standard ASTMD6751 (EUA) and EM 14213 (Europe). 
Average unsaturation (AU) was calculated from the compositional of fatty acid analysis as illustrate in Fig. 2-4. Each property was calculated using Equation. (1)-(7)

$$
\begin{gathered}
\mathrm{AU}=\sum \mathrm{N} \times \mathrm{C}_{\mathrm{i}} \\
\text { Viscosity }=-0.6316 \mathrm{AU}+5.2065 \\
\text { Specific gravity }=0.0055 \mathrm{AU}+0.8726 \\
\text { Cloud point }=-13.356 \mathrm{AU}+19.994 \\
\text { Cetane number }=-6.6684 \mathrm{AU}+62.876 \\
\text { Iodine number }=74.373 \mathrm{AU}+12.71
\end{gathered}
$$$$
\mathrm{HVV}=1.7601 \mathrm{AU}+38.534
$$

Where $\mathrm{N}$ is the number of carbon-carbon double bonds of unsaturated fatty acids while $\mathrm{C}_{\mathrm{i}}$ is the concentration (mass fraction) of the component.

\section{Results and discussion}

\subsection{Oleaginous yeast morphology}

$R$. toruloides, $R$. glutinis and $R$. graminis strains were notable oleaginous yeast because they were nonpathogenic species and good producer of carotenoides. They belong to red color basidiomycete. These strains showed different shade of pigments in their colony. Results showed that $R$. toruloides TISTR 5123 and TISTR 5154 revealed orangish-red color with ovidal to spherical cell shape Figure 1 (B1, B3, B7 and B8) For. $R$. toruloides TISTR 5149, it showed pink, circular, smooth, moist colonies. For Y. Lipolytica, which belong to Ascomycota division, showed yellowish to creamy white, irregular, wrinkled, moist colonies especially $Y$. lipolytica TISTR 5151 (Fig. 1).

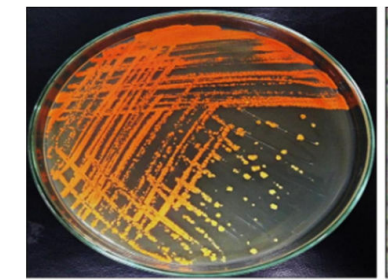

A1

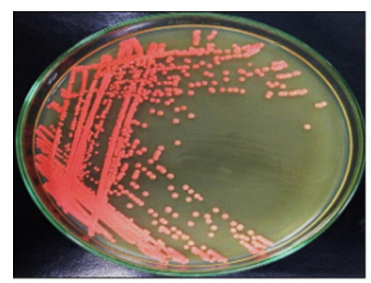

A3

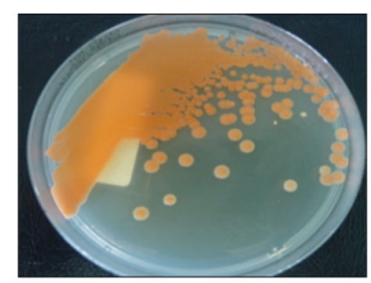

A7

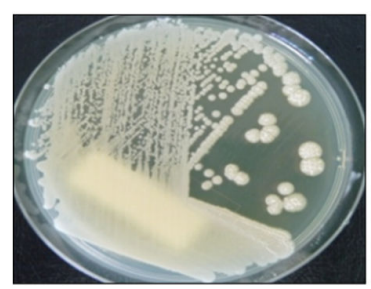

A6

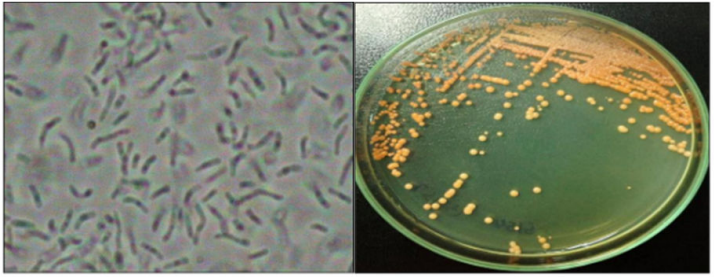

B1

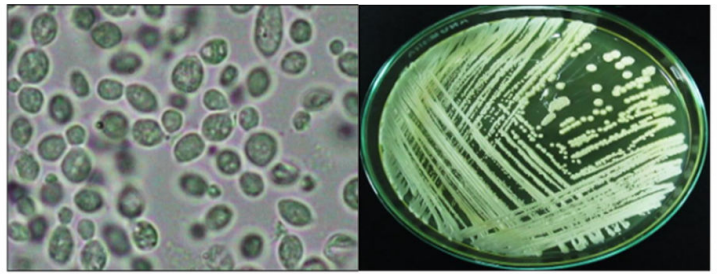

B3

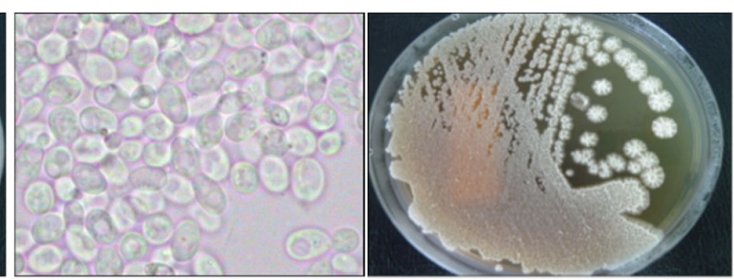

B7

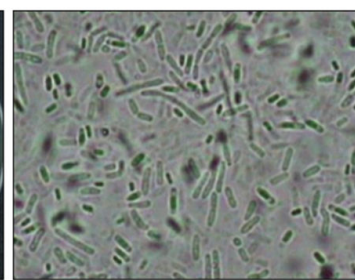

B6

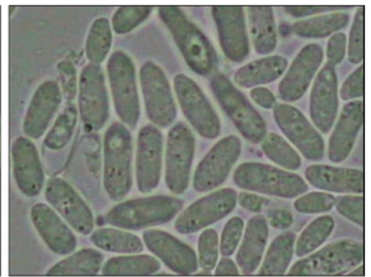

B2

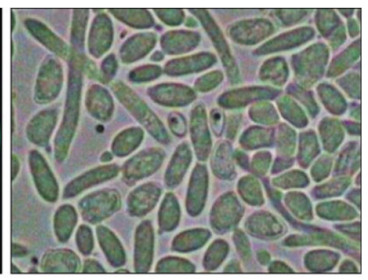

B4

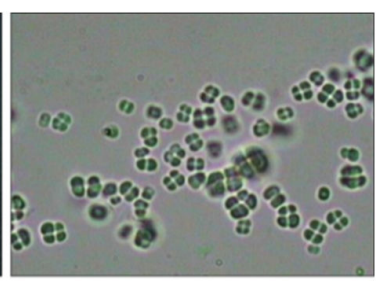

B5

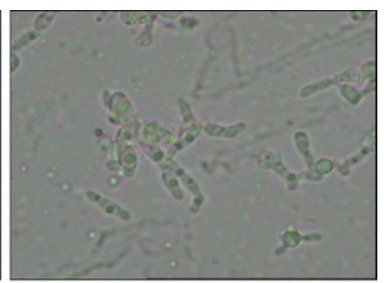

B8

Fig. 1. Oleaginous yeasts (A) in YMA media and (B) on microscopy with magnification of 1000X : (1) R. toruloides TISTR 5123, (2) R. toruloides TISTR 5154, (3) R. toruloides TISTR 5149, (4) Y. lipolytica TISTR 5054, (5) Y. lipolytica TISTR 5151, (6) Y. lipolytica TISTR 5621, (7) R. glutinis TISTR 5159 and (8) R. graminis TISTR 5124 (Towijit et al, 2014, [19]. 
To choose the suitable oleaginous yeast from eight oleaginous yeasts, the biomass production yield and cellular lipid content were determined as shown in Table 1. For our chosen strains of oleaginous yeasts, they are scattered among different groups in phylum Ascomycota and Basidiomycota. However, results showed all strains of $Y$. lypotica produced more biomass more than $R$. toruloides, $R$ glutinis and $R$. gramini, when grown in glucose. The yeast strain $Y$. lipotica TISTR 5054 gave the most biomass (3.469 \pm $0.301 \mathrm{~g} / \mathrm{L}$ ); however, $R$. glutinis TISTR 5159 produced the least biomass $(1.559 \pm 0.279 \mathrm{~g} / \mathrm{L})$ in glucose. Maximum intracellular lipid yield was attained by $Y$. lipotica $5151(3.377 \pm 0.259 \mathrm{~g} / \mathrm{L})$ followed by $Y$. lipotica $5054(0.595 \pm 0.034 \mathrm{~g} / \mathrm{L})$, Y. lipotica 5621 $(0.565 \pm 0.115 \mathrm{~g} / \mathrm{L})$ and $R$. toruloides TISTR 5149 $(0.450 \pm 0.044 \mathrm{~g} / \mathrm{L})$. $R$. toruloide TISTR 5154 gave the lowest lipid yield $(0.168 \pm 0.014 \mathrm{~g} / \mathrm{L})$ as shown in Table 1.

Once considered the industrial carbon source as molasses, the maximum cellular lipid content was attained by $R$. toruloide TISTR $5154 \quad(32.35 \%)$ followed by $Y$. lipotica 5054. (21.51\%), Y. lipotica $5151(21.09 \%)$. R. toruloide TISTR 5149 had the lowest lipid content $10.24 \%$. Comparison of crude glycerol growth in Table 1, only R.graminis could be considered as oleaginous yeast in this experiment. The lowest lipid productivity was found in $Y$. lipotica TISTR 5054. The high lipid percentage were varied in $R$. graminis TISTR 5124, R. toruloides TISTR 5123 and $R$. toruloides TISTR 5149. Our strains yield both biomass and lipid lower than other researchers reported. $R$. toruloides is a red basidiomycete, isolated from conifer, and is capable of accumulating up to $76 \%$ of lipids in glucose [20]. R. glutinis is able to accumulate up to $66 \%$ of it dry weight as lipids and can reach $72 \%$ liquid accumulation with glucose as the carbon source [21].

For cultivation in glucose, molasses and crude glycerol, the fatty acid profiles of each yeast were shown in Fig. 2-4. All strains contained mainly palmitic acid (C16:0), steric acid (C18:0), oleic acid (C18:1), and linoleic acid (C18:2) acids. Fatty acids of all strains contained lauric acid (C12:0). Six strains of oily yeast contained intracellular lipid more than $30 \%$ in glucose cultivation. The highest lipid production was $Y$. lipolytica TISTR 5621 yield more than $50 \%$ palmitic acid of those fatty acids in glucose cultivation.

The suitable selection for using molasses as the substrate was $R$. toluloides TISTR 5124 because of its yield of more than $40 \% \mathrm{C} 16: 0$, while the production of intracellular lipid cultured in glycerol showed that $Y$. lipolytica TISTR 5151 yielded over $40 \%$ of palmitic acid. Results revealed that $\mathrm{C} 18: 0, \mathrm{C} 18: 1$ and $\mathrm{C} 18: 2$ varied among strains and carbon sources. The suitability of microorganism-based biodiesel for application as a fuel requires certain properties similar to traditional biodiesel, and need to be fulfilled with the specification by internationals standards. These parameters may influence by the individual characteristics of fatty acid methyl ester (FAME). When fatty acids have little saturation, for example C16:0, C18:0, C18:1, C18:2 and C18:3, they are suitable for the production of biodiesel; on other hand, when rich in polyunsaturated fatty acids with four or more unsaturations, they become unsuitable due to their accountability to oxidation [22, 23].

Table 1. The biomass and lipid concentration of eight oleaginous yeasts in different carbon sources.

\begin{tabular}{lcccccc}
\hline & \multicolumn{5}{c}{ Carbon source } \\
\cline { 2 - 7 } \multicolumn{1}{c}{ Strains } & \multicolumn{2}{c}{ Glucose } & \multicolumn{2}{c}{ Molasses } & \multicolumn{2}{c}{ Crude glycerol } \\
\cline { 2 - 7 } & $\begin{array}{c}\text { Biomass } \\
\text { (g/L) }\end{array}$ & Lipid (g/L) & $\begin{array}{c}\text { Biomass } \\
(\mathbf{g} / \mathbf{L})\end{array}$ & Lipid (g/L) & $\begin{array}{c}\text { Biomass } \\
(\mathbf{g} / \mathbf{L})\end{array}$ & Lipid (g/L) \\
\hline R. glutinis TISTR 5154 & $2.139 \pm 0.297$ & $0.168 \pm 0.014$ & $0.544 \pm 0.019$ & $0.176 \pm 0.021$ & $0.376 \pm 0.002$ & $0.060 \pm 0.004$ \\
R. glutinis TISTR 5159 & $1.559 \pm 0.279$ & $0.449 \pm 0.005$ & $1.848 \pm 0.038$ & $0.264 \pm 0.050$ & $0.311 \pm 0.002$ & $0.051 \pm 0.009$ \\
R. toruloides TISTR 5123 & $2.013 \pm 0.116$ & $0.278 \pm 0.027$ & $1.046 \pm 0.087$ & $0.186 \pm 0.033$ & $0.4526 \pm 0.005$ & $0.076 \pm 0.004$ \\
R. toruloides TISTR 5149 & $2.305 \pm 0.137$ & $0.450 \pm 0.044$ & $2.363 \pm 0.009$ & $0.242 \pm 0.038$ & $0.3667 \pm 0.003$ & $0.061 \pm 0.003$ \\
R. graminis TISTR 5124 & $1.429 \pm 0.154$ & $0.399 \pm 0.045$ & $1.529 \pm 0.046$ & $0.302 \pm 0.067$ & $0.398 \pm 0.008$ & $0.086 \pm 0.004$ \\
Y. lipolytica TISTR 5054 & $3.469 \pm 0.301$ & $0.595 \pm 0.034$ & $1.417 \pm 0.174$ & $0.319 \pm 0.054$ & $0.602 \pm 0.049$ & $0.074 \pm 0.005$ \\
Y. lipolytica TISTR 5151 & $3.377 \pm 0.259$ & $0.829 \pm 0.049$ & $2.214 \pm 0.082$ & $0.467 \pm 0.046$ & $1.189 \pm 0.534$ & $0.167 \pm 0.003$ \\
Y. lipolytica TISTR 5621 & $3.306 \pm 0.167$ & $0.565 \pm 0.115$ & $2.274 \pm 0.092$ & $0.428 \pm 0.064$ & $1.105 \pm 0.157$ & $0.139 \pm 0.004$ \\
\hline
\end{tabular}




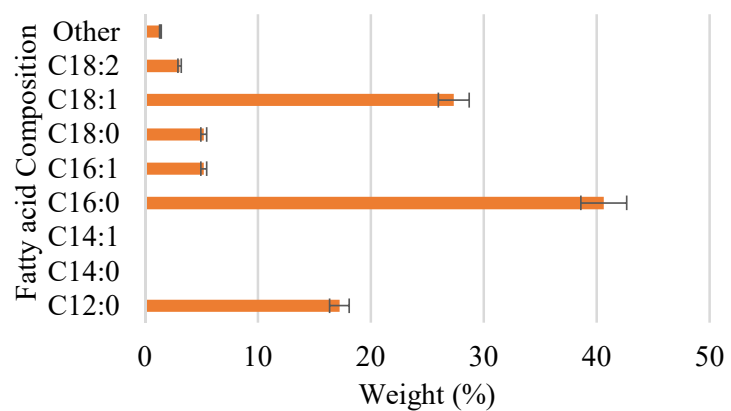

(a)

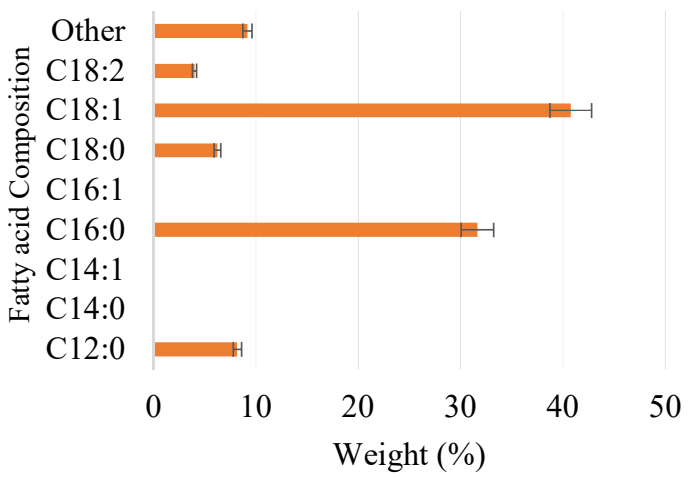

(c)

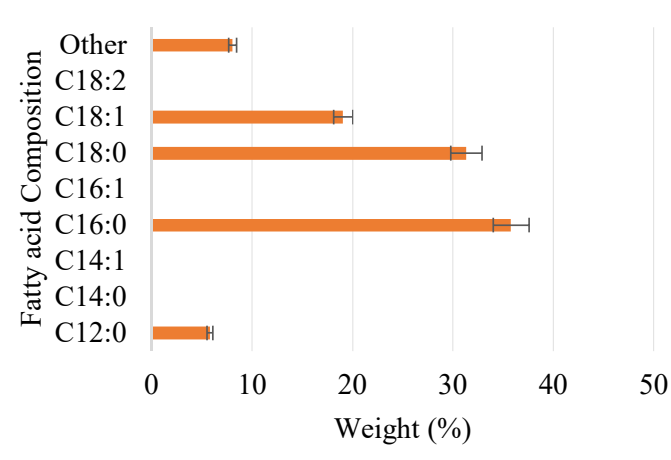

(e)

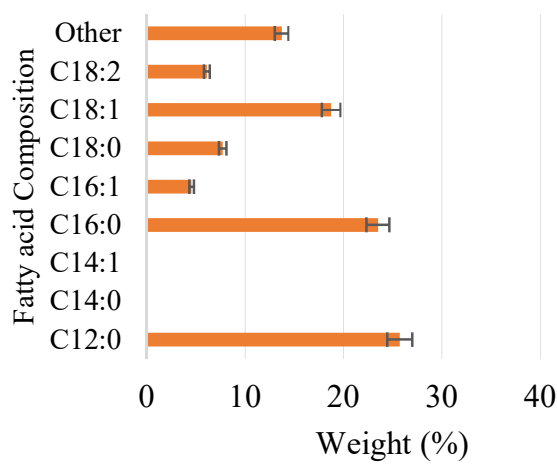

(g)

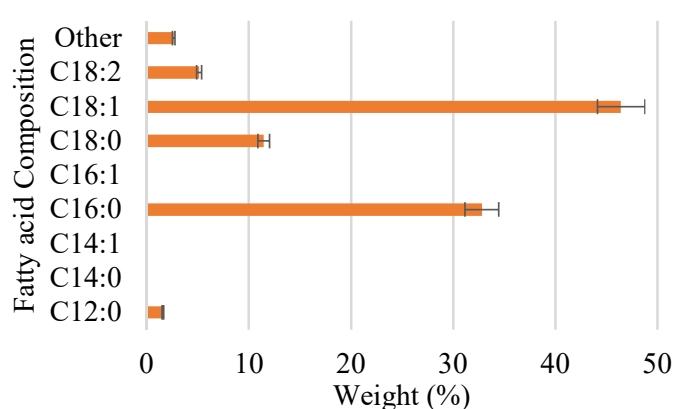

(b)

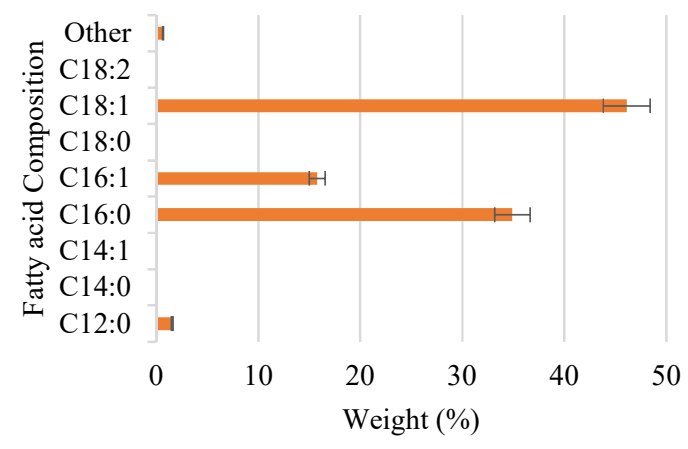

(d)

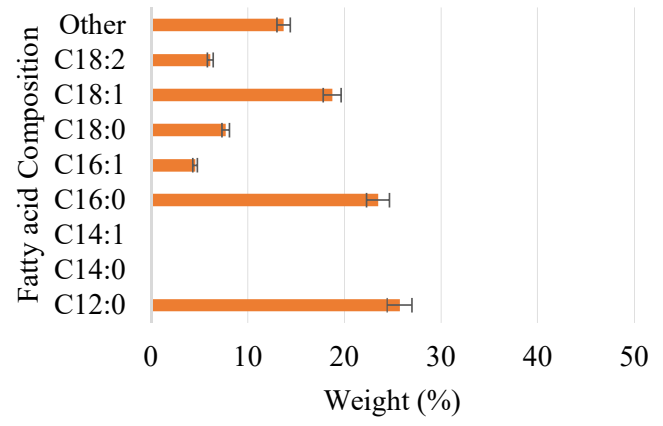

(f)

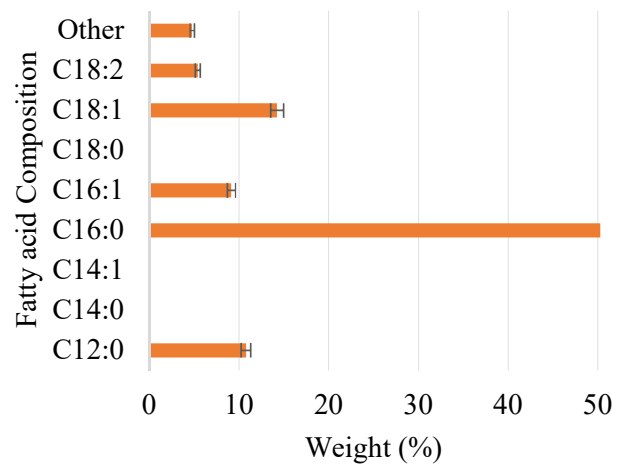

(h)

Fig.2. Compositional profiles of fatty acids from yeast cultivation in glucose (a) R. toluloides TISTR 5154, (b) R. toluloides TISTR 5159, (c) R. toluloides TISTR5123, (d) R. toluloides TISTR5149 (e) R. toluloides TISTR 5124, (f) Y. lipolytica TISTR 5054, (g) $Y$. lipolytica TISTR5151, and (h) Y. lipolytica TISTR 5621. 


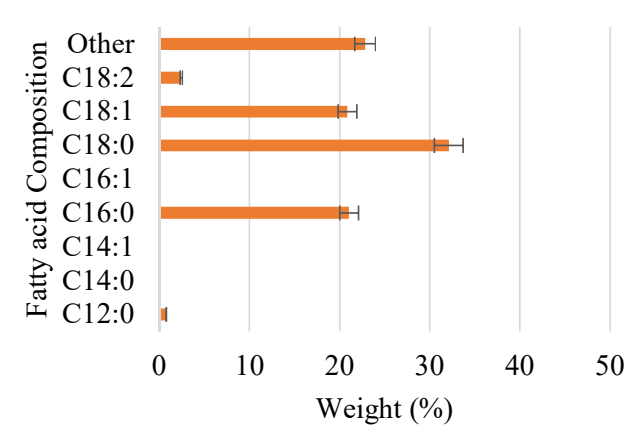

(a)

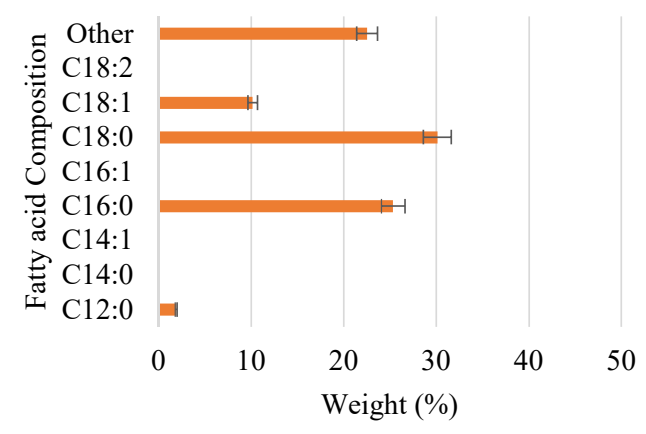

(c)

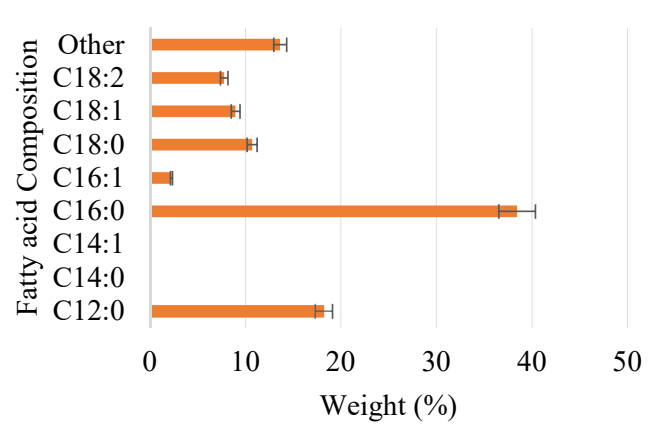

(e)

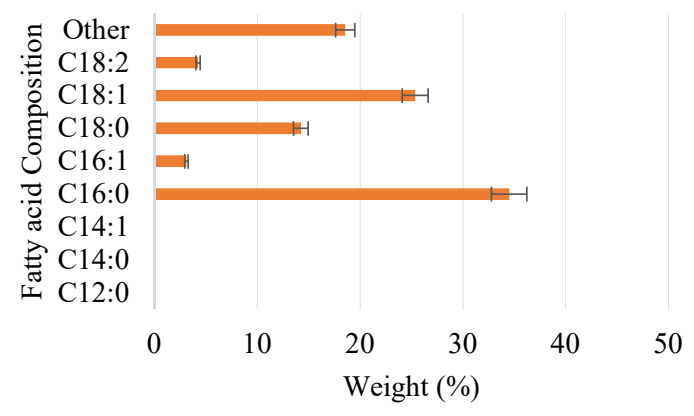

(g)

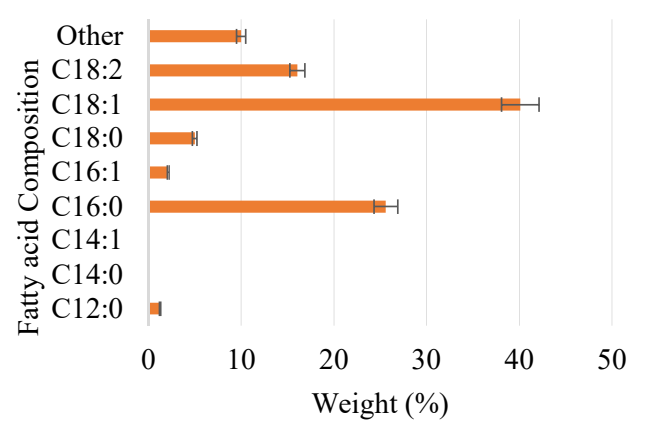

(b)

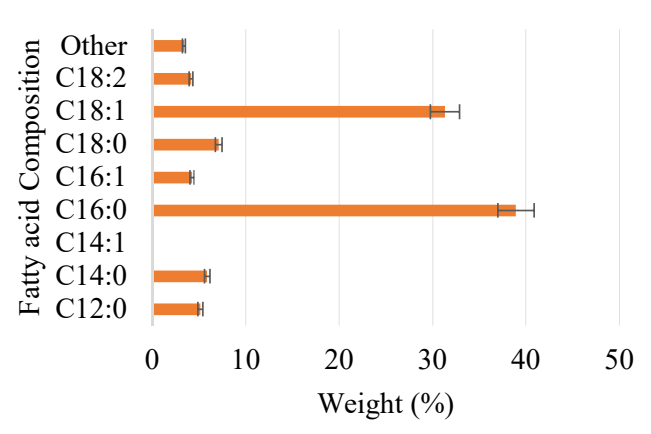

(d)

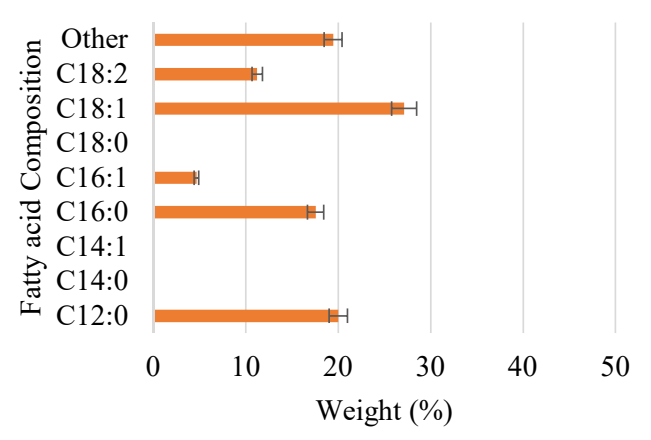

(f)

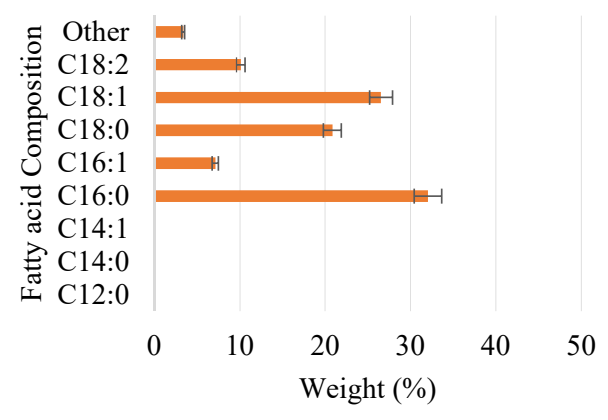

(h)

Fig. 3. Compositional profiles of fatty acids from yeast cultivation in molasses (a) R. toluloides TISTR 5154, (b) R. toluloides TISTR 5159, (c) R. toluloides TISTR5123, (d) R. toluloides TISTR5149 (e) R. toluloides TISTR 5124, (f) Y. lipolytica TISTR 5054, (g) Y. lipolytica TISTR5151, and (h) Y. lipolytica TISTR 5621. 


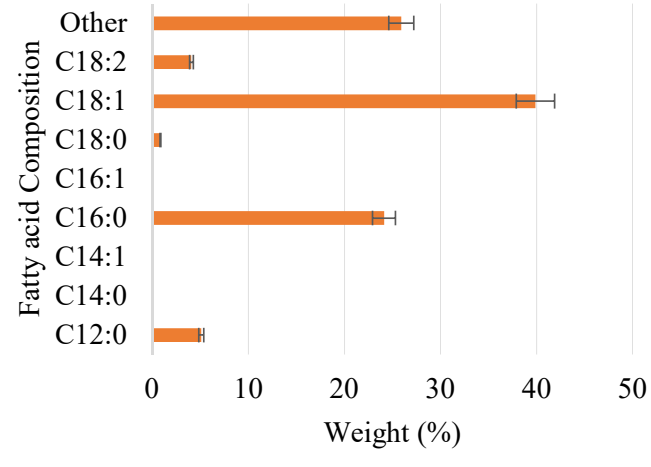

(a)

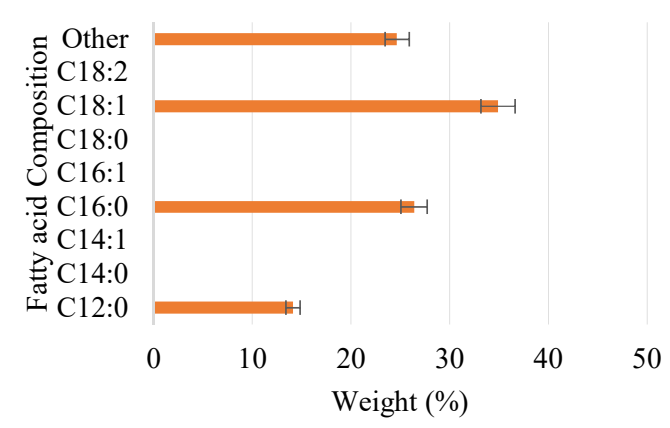

(c)

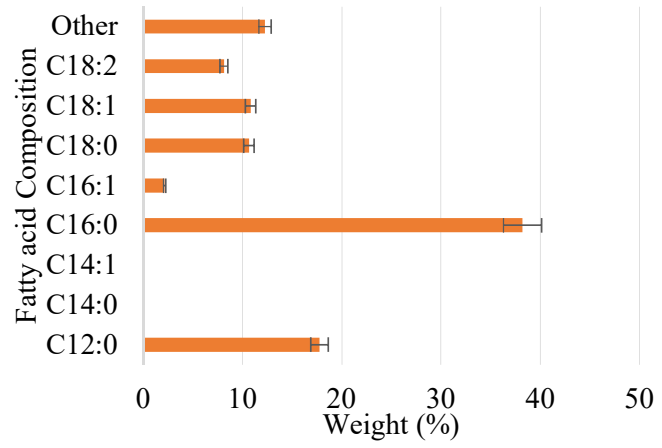

(e)

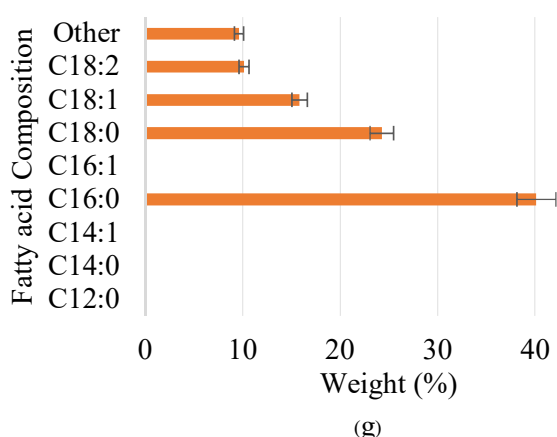

(g)

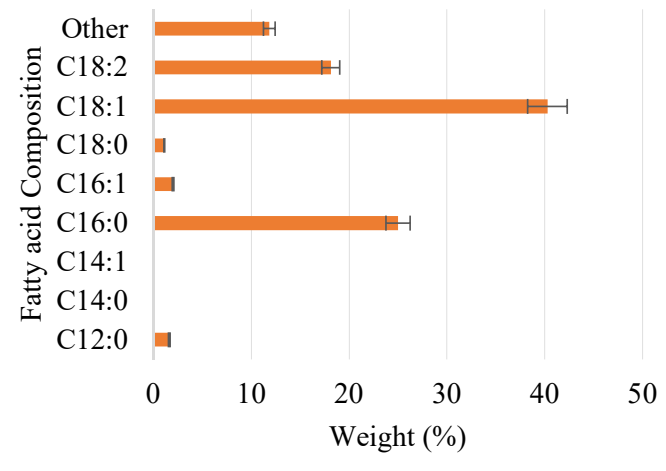

(b)

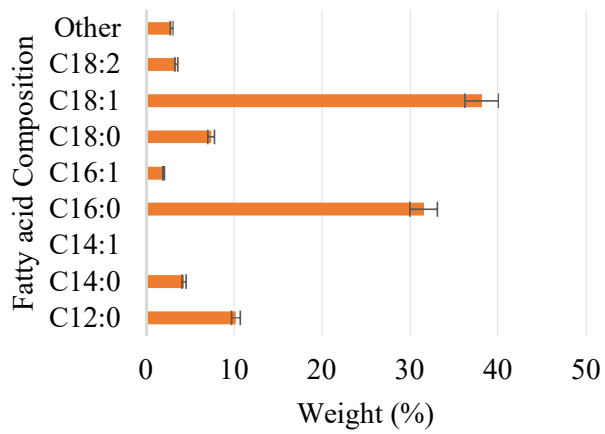

(d)

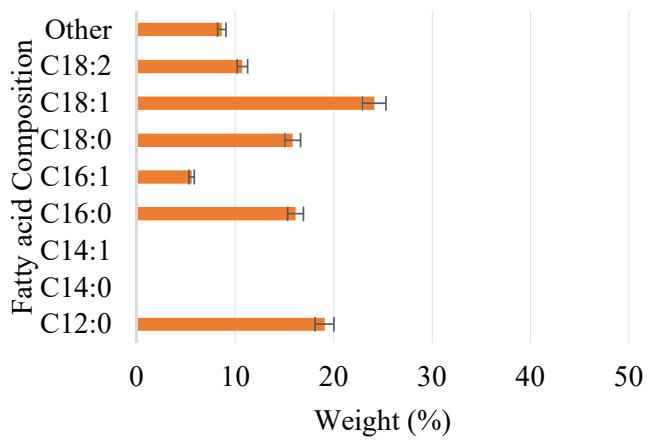

(f)

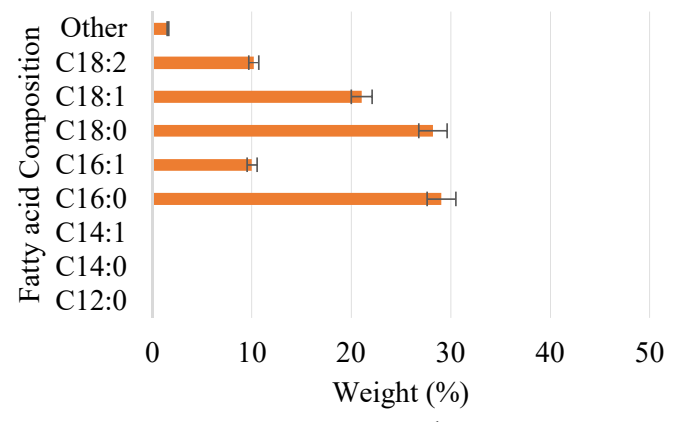

(h)

Fig. 4. Compositional profiles of fatty acids from yeast cultivation in glycerol (a) $R$. toluloides TISTR 5154, (b) R. toluloides TISTR 5159, (c) R. toluloides TISTR5123, (d) R. toluloides TISTR5149 (e) R. toluloides TISTR 5124, (f) Y. lipolytica TISTR 5054, (g) Y. lipolytica TISTR5151, and (h) Y. lipolytica TISTR 5621. 
In our study biodiesel properties were determined using the concentration (mass fraction) of the component, and the number of carbon-carbon double bonds of unsaturated fatty acids (Table 2-4). Results showed they were suitable for biodiesel production because they were rich in composition of C16:0, C18:0, $\mathrm{C} 18: 1$, and C18:2. Biofuels used in Europe are characterized by certain specification, which the content of linolenic ester acid (C18:2n6c) should not exceed $12 \%$ [24]. The main properties such as viscosity, specific gravity, cloud point, cetane number, iodine number and higher heating value (HHV) were directly reported to FAME. For biodiesel properties, a measurement of resistance to flow of a liquid results were showed in kinematic viscosity value [24], our data showed that viscosities of eight oleaginous yeast were within a narrow range of $4.00-5.30 \mathrm{~mm}^{2} / \mathrm{sec}$ of all carbon sources. Our yeast strains have slightly lower viscosity compared to palm oil, at $4.61 \mathrm{~mm}^{2} / \mathrm{sec}$. The ASTM D6751 viscosity specification of $1.9-6.0 \mathrm{~mm}^{2} / \mathrm{sec}$ was satisfied by all eight oleaginous yeasts. Additionally, double bond configuration influence viscosity with lower effects [25]. The more restrictive EN 14214 specification of $3.5-5.0 \mathrm{~mm}^{2} / \mathrm{sec}$ excluded almost yeast strains, except $Y$. lipolytica TISTR 5621 and $R$. graminis TISTR 5124 (Table 3).

Viscosity value normally related to the degree of unsaturation with higher unsaturation resulting in lower viscosity. For specific gravity varied within a narrow range of 0.8726-0.8750 for all eight yeast strains. Palmderived FAME had the lowest specific gravity value of 0.873 , while jatropa oil yielded 0.876 (Table 2-4). Biodiesel of our selected yeasts would meet the specification of the EN 14214 standard. For ASTM D6751 standard did not include a specific density. Cloud point showed similar pattern across the strains and carbon sources. Low temperature performance as represented in cloud point value showed satisfaction of biodiesel users. Normally, biodiesel from palm oil showed the poorest performance.
This cloud point can be used to determine the suitability of biodiesel fuels in use. However, both U.S. and European biodiesel standard did not include explicit specification for this property.

Cetane number is the influential value that showed a measurement of an autoignition quality characteristics. These cetane values for all eight yeast cultures in all carbon sources easily overcome the ASTM miminum specification of 47 with the highest cetane value being observed for oleaginous yeast grown on glucose (Table 3 ). The cetane numbers of FAME fuels obviously varied with average degree of unsaturation of fatty acid. Another properties, iodine value (IV) was a measurement for determination of FAME unsaturation. Our experiment showed that ASTM D6751 did not include a specification for IV. All strains showed in Table 3-5 passed the EN 14214 that has a maximum IV of $120 \mathrm{mgI}_{2} / 100 \mathrm{~g}$ FAME. Lastly, higher heating value related to the amount of the fatty acid carbon chain increased the mass fraction of oxygen decreased; therefore, the heating value increased [26-28].

\section{Conclusion}

The fatty acid profiles of eight oleaginous yeast strains were summarized and compared with commercial compositional variability. They contained C16:0, C18:0, and C18:1 and C18:2 and higher levels of polyunsaturated fatty acid that potentially considered to be an alternative feedstock under cultivation with three different carbon sources, glucose, molasses and crude glycerol. However, more researches on optimization of cultivation condition including varying carbon to nitrogen ratio, cultivation time and temperature have to be further investigated.

This work supported by grant from the Thailand Research Fund (Grant no. KMUTNB-GOV-57-22).

Table 2. Comparison of biodiesel properties from cultured oleaginous yeasts in glucose.

\begin{tabular}{|c|c|c|c|c|c|c|}
\hline Yeast strains & $\begin{array}{c}\text { Viscosity } \\
\left(\mathrm{mm}^{2} / \mathrm{s}\right)\end{array}$ & $\begin{array}{c}\text { Specific } \\
\text { gravity }\end{array}$ & $\begin{array}{c}\text { Cloud } \\
\text { point }\left({ }^{\circ} \mathrm{C}\right)\end{array}$ & $\begin{array}{l}\text { Cetane } \\
\text { number }\end{array}$ & $\begin{array}{c}\text { Iodine } \\
\text { number }\end{array}$ & $\begin{array}{c}\text { HHV } \\
(\mathrm{MJ} / \mathrm{kg})\end{array}$ \\
\hline Rhodosporidium toruloides TISTR 5123 & 5.21 & 0.8726 & 19.99 & 62.88 & 12.71 & 38.53 \\
\hline Rhodosporidium toruloides TISTR 5154 & 5.21 & 0.8726 & 19.99 & 62.88 & 12.71 & 38.53 \\
\hline Rhodosporidium toruloides TISTR 5149 & 5.21 & 0.8726 & 19.99 & 62.88 & 12.71 & 38.53 \\
\hline Yarrowia lipolytica TISTR 5054 & 5.21 & 0.8726 & 19.99 & 62.88 & 12.71 & 38.53 \\
\hline Yarrowia lipolytica TISTR 5151 & 5.04 & 0.8740 & 16.57 & 61.17 & 31.77 & 38.99 \\
\hline Yarrowia lipolytica TISTR 5621 & 5.14 & 0.8732 & 18.63 & 62.19 & 20.33 & 38.71 \\
\hline Rhodotorula glutinis TISTR 5159 & 5.21 & 0.8726 & 19.99 & 62.88 & 12.71 & 38.53 \\
\hline Rhodotorula graminis TISTR 5124 & 5.21 & 0.8726 & 19.99 & 62.88 & 12.71 & 38.53 \\
\hline Palm oil $^{\mathrm{a}}$ & 4.61 & 0.8730 & 14.0 & 61.9 & 54.0 & 40.6 \\
\hline Jatropa oil $^{\mathrm{a}}$ & $\begin{array}{c}4.48 \\
(4.75)\end{array}$ & $\begin{array}{l}0.8789 \\
(0.876)\end{array}$ & $\begin{array}{c}4.67 \\
(5)\end{array}$ & $\begin{array}{l}55.23 \\
(55.7)\end{array}$ & $\begin{array}{c}98.20 \\
(109.5)\end{array}$ & $\begin{array}{l}40.55 \\
(40.7)\end{array}$ \\
\hline US biodiesel standard ASTM D6751 ${ }^{\mathrm{a}}$ & $1.9-6.0$ & - & - & $47 \mathrm{~min}$ & - & - \\
\hline EU Biodiesel standard EN 14214a & $3.5-5.0$ & $0.86-0.9$ & - & $51 \mathrm{~min}$ & $120 \max$ & - \\
\hline
\end{tabular}

${ }^{\mathrm{a}}$ The reference of values palm oil, Jatropa oil, the US biodiesel and EU biodiesel standards are from Hoekman, 2012. 
Table 3. Comparison of biodiesel properties from cultured oleaginous yeasts in molasses

\begin{tabular}{lcccccc}
\hline \multicolumn{1}{c}{ Yeast strains } & $\begin{array}{c}\text { Viscosity } \\
\left(\mathbf{m m}^{2} / \mathbf{s}\right)\end{array}$ & $\begin{array}{c}\text { Specific } \\
\text { gravity }\end{array}$ & $\begin{array}{c}\text { Cloud } \\
\text { point }\left({ }^{\circ} \mathbf{C}\right)\end{array}$ & $\begin{array}{c}\text { Cetane } \\
\text { number }\end{array}$ & $\begin{array}{c}\text { Iodine } \\
\text { number }\end{array}$ & $\begin{array}{c}\text { HHV } \\
(\mathbf{M J} / \mathbf{k g})\end{array}$ \\
\hline Rhodosporidium toruloides TISTR 5123 & 5.21 & 0.8726 & 19.99 & 62.88 & 12.71 & 38.53 \\
Rhodosporidium toruloides TISTR 5154 & 5.01 & 0.8743 & 15.86 & 60.81 & 35.71 & 39.08 \\
Rhodosporidium toruloides TISTR 5149 & 5.21 & 0.8726 & 19.99 & 62.88 & 12.71 & 38.53 \\
Yarrowia lipolytica TISTR 5054 $_{\text {Yarrowia lipolytica TISTR 5151 }}^{4.61}$ & 0.8778 & 7.36 & 56.57 & 83.07 & 40.20 \\
Yarrowia lipolytica TISTR 5621 $_{\text {Rhodotorula glutinis TISTR 5159 }}^{5.21}$ & 0.8726 & 19.99 & 62.88 & 12.71 & 38.53 \\
Rhodotorula graminis TISTR 5124 $_{\text {Palm oil }}^{\mathrm{a}}$ & 4.98 & 0.8745 & 15.31 & 60.54 & 38.80 & 39.15 \\
Jatropa oil & 4.93 & 0.8750 & 14.16 & 59.97 & 45.17 & 39.30 \\
& 5.04 & 0.8741 & 16.45 & 61.11 & 32.42 & 39.00 \\
US biodiesel standard ASTM D6751 $^{\mathrm{a}}$ & 4.61 & 0.8730 & 14.0 & 61.9 & 54.0 & 40.6 \\
EU Biodiesel standard EN 14214 $^{\mathrm{a}}$ & 4.48 & 0.8789 & 4.67 & 55.23 & 98.20 & 40.55 \\
\hline
\end{tabular}

aThe reference of values palm oil, Jatropa oil, the US biodiesel and EU biodiesel standards are from Hoekman, 2012.

Table 4. Comparison of biodiesel properties from cultured oleaginous yeasts in glycerol.

\begin{tabular}{lcccccc}
\hline \multicolumn{1}{c}{ Yeast strains } & $\begin{array}{c}\text { Viscosity } \\
\left(\mathbf{m m}^{2} / \mathbf{s}\right)\end{array}$ & $\begin{array}{c}\text { Specific } \\
\text { gravity }\end{array}$ & $\begin{array}{c}\text { Cloud } \\
\text { point }\left({ }^{\circ} \mathbf{C}\right)\end{array}$ & $\begin{array}{c}\text { Cetane } \\
\text { number }\end{array}$ & $\begin{array}{c}\text { Iodine } \\
\text { number }\end{array}$ & $\begin{array}{c}\text { HHV } \\
(\mathbf{M J} / \mathbf{k g})\end{array}$ \\
\hline Rhodosporidium toruloides TISTR 5123 & 5.21 & 0.8726 & 19.99 & 62.88 & 12.71 & 38.53 \\
Rhodosporidium toruloides TISTR 5154 & 5.15 & 0.8731 & 18.73 & 62.24 & 19.77 & 38.70 \\
Rhodosporidium toruloides TISTR 5149 & 5.21 & 0.8726 & 19.99 & 62.88 & 12.71 & 38.53 \\
Yarrowia lipolytica TISTR 5054 $_{\text {Yarrowia lipolytica TISTR 5151 }}$ & 5.21 & 0.8726 & 19.99 & 62.88 & 12.71 & 38.53 \\
Yarrowia lipolytica TISTR 5621 $_{\text {Rhodotorula glutinis TISTR 5159 }}^{5.00}$ & 0.8744 & 15.63 & 60.69 & 37.04 & 39.11 \\
Rhodotorula graminis TISTR 5124 $_{\text {Palm oil }}^{\mathrm{a}}$ & 5.96 & 0.8748 & 14.68 & 60.22 & 42.30 & 39.23 \\
Jatropa oil $^{\mathrm{a}}$ & 5.21 & 0.8726 & 19.99 & 62.88 & 12.71 & 38.53 \\
& 4.61 & 0.8726 & 19.99 & 62.88 & 12.71 & 38.53 \\
US biodiesel standard ASTM D6751 $^{\mathrm{a}}$ & 4.48 & 0.8730 & 14.0 & 61.9 & 54.0 & 40.6 \\
EU Biodiesel standard EN 14214 $^{\mathrm{a}}$ & $1.9-6.0$ & - & 4.67 & 55.23 & 98.20 & 40.55 \\
\hline
\end{tabular}

aThe reference of values palm oil, Jatropa oil, the US biodiesel and EU biodiesel standards are from Hoekman, 2012.

\section{References}

1. S.K. Hoekman, A. Broch, C. Robbins, E. Ceniceros, M. Natarajan, Renew Sustain Energy Rev. 16 (2012)

2. C. Ratledgen, Biochimie 86 (2004)

3. C. Ratledge, J.P. Wynn, Adv Appl Microbiol. 51 (2002)

4. C.R. Soccol, C.J.D. Neto, V.T. Soccol, E.B. Sydney, E.S.F. Costa, A.B.P. Medeiros, L.P.S. Vandenberghe, Bioresour Technol. 223 (2017)

5. J. M. Ageitos, J. A. Vallejo, P. V. Crespo, T. G. Villa, Appl Microbiol Biotechnol. 90 (2011)

6. S. Papanikolaou, G. Aggelis, Eur J Lipid Sci Technol. 113 (2011)

7. S. Wu, C. Hu, C. Jin, X. Zhao, Z.B. Zhao, Bioresour Technol. 101 (2010)
8. Y.H. Li, Z.B. Zhao, F.W. Bai, Enz Microb Technol. 41 (2007)

9. S. Papanikolaou, G. Aggelis, Lipid Technol. 21 (2009)

10. S. Papanikolaou, G. Aggelis, Eur J Lipid Sci Technol. 112 (2010)

11. X. Meng, J. Yang, X. Xu, L. Zhang, Q. Nie, M. Xian, Renew Energy 34 (2009)

12. I. Sitepu, T. Selby, T. Lin, S. Zhu, B.M. Kyria, J Ind Microbiol Biotechnol. 41 (2014)

13. M.M.K. Bagy, M.H. Abd-Alla, F.M. Morsy, E.A. Hassan, Int J Hydrog Energy 39 (2014)

14. D. Yan, Y. Lu, Y.F. Chen, Q. Wu, Soccool Bioresour Technol. 102 (2011)

15. E.R. Easterling, W.T. French, R. Hernandez, M. Licha, Bioresour Technol. 100 (2009) 
16. C. Kobkam, J. Tinoi, S. Kittiwachana, KMUTNB Int J Appli Sci Technol. 11 (2018)

17. A.E. Atabani, A.S. Silitonga, I.A. Badruddin, T.M.I. Mahlia, H.H. Masjuki, S. Mekhilef, Renew Sust Energ Rev. 16 (2012)

18. E.G. Bligh, W.J. Dyer, Can J Biochem Physiol. 37 (1959)

19. U. Towijit, C. Amponpiboon, M. Sriariyanun, S. Kongruang, Suranaree J Sci Technol. 21 (2014)

20. Q. Li, W. Du, D. Liu, Appl Microbiol Biotechnol. 80 (2008)

21. A. Beopoulos, J. Cescut, R. Haddouche, J.L. Uribelarrea, J.C. Molina, J.M. Nicaud, Prog Lipid Res. 48 (2009)
22. P. Dey, J. Banerjee, M.K. Maiti, Bioresour Technol. 102 (2011)

23. A. Gopinath Sukumar Puhan, G. Nagarajan, Renew Energy 34 (2009)

24. G. Knothe, SAE Tech Pap. (2005)

25. J.B. Hu, Z.X. Du, C.X. Li, E. Min, Fuel 84 (2005)

26. A. Demirbas, Fuel 77 (1998)

27. A. Demirbas, Fuel 87 (2008).

28. T. Wuttilerts, S. Chulalaksananukul, P. Peerapongpipat, P. Suksommanat. Appl Sci Eng Prog. 12 (2019) 